\title{
Erratum to: Social Impact of Dialysis on Children and Their Families
}

\author{
Jameela Abdulaziz Kari • Majed Alzahrany • \\ Basem El-Deek • Muhanad Maimani • Sherif El-Desoky
}

Published online: 9 May 2014

(C) Dr. K C Chaudhuri Foundation 2014

Erratum to: Indian J Pediatr

DOI:10.1007/s12098-013-1236-Z

The original version of this article unfortunately contained a mistake.

In Abstract, under Results section, the numerical value 22 should be replaced with 20 . It should read as "Thirty six children (20 boys and 16 girls)...".

The online version of the original article can be found at http://dx.doi.org/ doi:10.1007/s12098-013-1236-z.

J. A. Kari $(\bowtie) \cdot$ M. Alzahrany • B. El-Deek · M. Maimani •

S. El-Desoky

Department of Pediatrics, King Abdulaziz University, PO Box

80215, Jeddah 21589, Kingdom of Saudi Arabia

e-mail: jkari@doctors.org.uk

B. El-Deek

Department of Medical Education, King Abdulaziz University,

Jeddah, Kingdom of Saudi Arabia 